\section{Molluscan delights}

Pseudothecosemata, Gymnosomata and Heteropoda (Gastropoda). By S. Van Der Spoel. Pp. 484. (Bohn, Scheltema and Holkema: Utrecht, 1976.)

As once aptly observed by Dr Joel Hedgpeth, taxonomy is man's oldest profession, his "first task in the Garden was not to work for his living - that came after the Fall-but to name every beast of the field and every fowl of the air". Too soon interrupted in this, it has been left to succeeding generations to complete a task which increased in size with every new exploration, including the waters of the sea, and with every development in the capacity for magnification.

The significance of taxonomy was enhanced with the demonstration of the fact of evolution. What had been accepted as the works of a highly ingenious, if in certain aspects a by no means beneficent, Creator now appeared as the contemporary endpoints of innumerable, often interlocking, lines of evolutionary change. Taxonomy records the outcome of the most significant sequences of events that have occurred during the history of this planet.

To a marine malacologist it is difficult to imagine two more fascinating groups than prosobranch Heteropoda and opisthobranch Pteropoda (Euthecosomata, Pseudothecosomata and Gymnosomata) evolving independently as holoplanktonic gastropods. It is a delight to see with what elegance they are treated in this volume by $\operatorname{Dr} S$. Van Der Spoel of the Institute of Taxonomic Zoology, Amsterdam. It succeeds an earlier one, in 1967, dealing solely with the Euthecosomata and is to be followed by a third concerned with the biology of all planktonic molluscs.

This surely is an ideal example of the manner in which the products of evolution should be treated with adequate description and synonomy of every species, accompanied by 166 beautifully drawn line figures-and how fully these exquisite animals merit such attention-followed by 81 maps showing world distribution. Appendices contain diagrams revealing the diversity of taxa in the different faunal centres with others assisting in the use of keys for identifying species difficult to separate, notably in the heteropod Atlantidae. Recent information about the Euthecosomata brings the earlier volume up-to-date, and a reference list of over 80 pages covers the entire literature.

Differing widely in origin, the heteropods and pteropods differ also in distribution, a possible consequence of their different periods of origin. There are more heteropods in the IndoPacific but pteropods are commoner in the Atlantic. From this it is postulated that the former evolved in the greater oceanic area. But, being more thermophilous, they found difficulty in passing through colder southern waters into the Atlantic. They are not, however, absent in that ocean and nowhere do more spectacular species of both groups live together than in the Mediterranean, where this reviewer has found much pleasure in studying living representatives.

Dr Van Der Spoel's book is a work of combined scholarship and research and forms a permanent addition of the highest value to zoological knowledge. It should be contained in every museum, every marine laboratory and every University library. It is an indispensible work of reference to marine biologists, both applied and academic. It will be a delight to every malacologist.

\section{M. Yonge}

Sir Maurice Yonge, formerly Professor of Zoology at Bristol, then at Glasgow, is Honorary Fellow in the University of Edinburgh, $U K$.

\section{Biology of Kinetoplastid flagellates}

Biology of the Kinetoplastida. Vol. 1. Edited by W. H. R. Lumsden and D. A. Evans. Pp. xxvi+563. (Academic: London, New York and San Francisco, 1976.) $£ 18.00$.

THE parasitic members of the flagellate order Kinetoplastida of the phylum Protozoa have always attracted more attention than the free-living forms, and the species of two genera, Trypanosoma and Leishmania, which infect man, have attracted the most. It is easy to forget that these genera are only two out of sixteen or more, that many trypanosomes cause no harm to their hosts and that it might be possible to learn as much about trypanosomiasis and leishmaniasis from comparative studies on related forms as from the trypanosomes and leishmanias of man.

To many protozoologists, the literature is top-heavy with information on the Kinetoplastid flagellates of medical and veterinary importance and it is the intention of this multi-author volume (and its companion when it is published) to redress this imbalance and to present the Kinetoplastida as a whole. Difficult as this is to achieve, it looks as if the two volumes between them will do just that.

This volume, for a number of reasons explained by the editors, is mainly concerned with trypanosomes, apart from the first two chapters (by $\mathrm{K}$. Vickerman, and K. Vickerman and T. M. Preston) which deal with the diversity and cell biology of the kinetoplastid flagellates as a whole. Both these chapters contain a considerable amount of original thought and research material. There are also four comprehensive reviews of trypanosomes, of birds (J. R. Baker), of bats (C. J. Marinkelle), of primates other than man (C. J. Marinkelle) and of the subgenus Herpetosoma (D. $\mathrm{H}$. Molyneux). These, with their well presented tables and check lists, will be invaluable sources of information for years to come.

Two of the remaining chapters cover the rapidly advancing fields of the biochemical aspects of taxonomy (B. A. Newton) and oxidative metabolism (I. B. R. Bowman and I. W. Flynn). Informative and useful as these are at present they will be even more useful when read in conjunction with the chapters on the taxonomy of the leishmanias and biochemical aspects of Trypanosoma cruzi which are pro. mised in volume 2 .

Two further chapters deal with the subgenus Megatrypanum (E. A. Wells) and Trypanosoma rangeli (A. D'Alessandro). Although their inclusion can be justified on the grounds that the information contained in them is not adequately summarised elsewhere, they are really too specialised to justify such extensive coverage in a book of this kind. The remaining two chapters on innate resistance to trypanosome infection (R. J. Terry) and antigenic variation (A. R. Gray and A. G. Luckins) are again rather specialised, and would have been better associated with other papers on immunity also due to be published in volume 2 . In any case, antigenic variation could do with a rest from reviews for a year or so.

This is a most valuable work of reference but could have been so much better if the reproduction of the plates and electron micrographs had been of better quality, and if all the chapters had been updated from their original 1973 form as some of them have been. The publication of volume 2 is eagerly awaited. Perhaps it would not be too much to hope that each chapter in volume 1 will be briefly updated and that better quality paper will be used for the plates.

F. E. G. Cox

F. E. G. Cox is Professor of Zoology in the School of Biological Sciences at King's College, University of London, UK. 